\title{
Article \\ Polylactic Acid and Polycaprolactone Blended Cosmetic
Microneedle for Transdermal Hispidin Delivery System
}

\author{
Seungyeon Lee ${ }^{1,+} \mathbb{D}$, Jihye Lee ${ }^{2,+}$, Kanghyun Choi ${ }^{2,+}$, Hyoseon Kim ${ }^{2}$, Youngkum Park ${ }^{2, *}$, Juhee Yoon ${ }^{3}$, \\ June Hyun $\operatorname{Kim}^{4, *}$ and Seongwoo Ryu ${ }^{1, *}$
}

1 Department of Materials Science and Engineering, The University of Suwon, 17 Wauan-gil, Bongdam-eup, Hwaseong-si 18323, Gyeonggi-do, Korea; sygm09@naver.com

2 Gragem Co., Ltd., Incheon 21999, Korea; poster35@gragem.com (J.L.); hyuny24k@gragem.com (K.C.); sunny77sun@gragem.com (H.K.)

3 Department of Polymer Science and Engineering, Inha University, Incheon 402-751, Korea; yoonjh0803@naver.com

4 Department of Biotechnology, The University of Suwon, 17 Wauan-gil, Bongdam-eup, Hwaseong-si 18323, Gyeonggi-do, Korea

* Correspondence: ykumpark@gragem.com (Y.P.); jk8199@suwon.ac.kr (J.K.); ryu@suwon.ac.kr (S.R.); Tel.: +82-032-458-5566 (Y.P.); +82-031-220-2519 (J.K.); +82-010-7367-0131 (S.R.)

+ All authors contributed equally to this work.

Citation: Lee, S.; Lee, J.; Choi, K.; Kim, H.; Park, Y.; Yoon, J.; Kim, J.; Ryu, S. Polylactic Acid and Polycaprolactone Blended Cosmetic Microneedle for Transdermal Hispidin Delivery System. Appl. Sci. 2021, 11, 2774. https://doi.org/ 10.3390/app11062774

Academic Editor: Giuseppe Perale

Received: 1 March 2021

Accepted: 16 March 2021

Published: 19 March 2021

Publisher's Note: MDPI stays neutral with regard to jurisdictional claims in published maps and institutional affiliations.

Copyright: (c) 2021 by the authors. Licensee MDPI, Basel, Switzerland. This article is an open access article distributed under the terms and conditions of the Creative Commons Attribution (CC BY) license (https:/ / creativecommons.org/licenses/by/ $4.0 /)$.

\begin{abstract}
Microneedles (MNs) are a new system of effective drug delivery that create micronsized pathways to the epidermis or upper dermis regions of the skin. In this study, we developed coated-type microneedles for direct hispidin delivery to the skin. Hispidin is a well-known plantderived antioxidant component showing antitumor, anti-inflammatory, antiallergic, antiangiogenic, antioxidant, hypoglycemic, hypolipidemic, and immunomodulatory activities. Polymeric blends of polylactic acid (PLA) and polycaprolactone (PCL) were casted as MNs to enhance skin permeability. PLA/PCL MNs exhibited the highest strength of 51.26 MPa with a width of $200 \mathrm{um}$. Hispidin was directly coated onto the MNs with PLA/PCL blends to form delivery layers. Compared to the hispidin-only delivery layer, skin permeability of hispidin increased by over $50 \%$ when using agarose gel in in vitro tests. In a dose-dependent manner, hispidin coated on PLA/PCL MNs also showed a brightening effect, as well as anti-inflammatory activity at the gene and protein level in skin cell culture experiments. It also demonstrated antimicrobial activity, and showed no cytotoxicity to skin cells. These results suggest that the PLA/PCL MN system with hispidin may have great potential as a prototype platform for various drug delivery systems, allowing the development of more effective subcutaneous delivery of vaccines, oligonucleotides, insulin, and many other cosmetic applications.
\end{abstract}

Keywords: microneedles; hispidin; drug delivery

\section{Introduction}

Compared to topical and transdermal delivery systems, microneedles (MNs) have advantages for delivering drugs through the transdermal route $[1,2]$. The stratum corneum layer is a major barrier for delivering drugs, allowing only limited, low-molecular-weight drugs to pass through it $[3,4]$. MNs are micron-sized needles that allow hydrophilic high-molecular-weight compounds to pass through the stratum corneum, allowing drug molecules to enter the skin [5-7]. Recently, different types of MNs have been investigated, including coated, solid, hollow, and hydrogel systems. The major purpose of MNs is to deliver drugs into the epidermis via pathways created by MNs [8-11].

Hispidin (4-O- $\beta$-D-glucopyranoside) is a yellowish natural substance present in Phellinus linteus, which can be synthesized using a general method. Its structural features are similar to aromatic compounds such as $\alpha$-tocopherol and other phenolic antioxidants, exhibiting a double bond with a benzene ring. Hispidin, a polyphenol compound isolated from Phellinus linteus, has been reported to possess antioxidant activity [12]. Its antioxidant 
activity is about 3-5 times that of water-soluble vitamin E, equivalent to the reported value for beta hydroxy acid (BHA). Recently, it was also demonstrated that hispidin can inhibit the macrophage-mediated inflammatory response by downregulating nuclear factor kappa-light-chain-enhancer of activated B cells (NF- $\mathrm{kB}$ ) activations [13]. Hispidin also inhibits palmitate-induced apoptotic nuclear condensation in mouse myoblast cell line (C2C12) [14]. Hispidin is effective due to its anti-p21 activated kinase 1 (PAK1) activity. As expected, PAK1 silencing clearly reduced the melanogenic activity of this cell line by around $50 \%$, proving that PAK1 is essential for alpha-melanocyte stimulating hormone (MSH)-induced melanogenesis [15]. In a prior study, aimed at identifying active oxygen degradation and whitening effects, 1,2 , and $5 \mu \mathrm{M}$ concentrations of hispidin were confirmed to decrease melanin production. Hispidin, a polyphenolic substance, identified as 6-(3,4-dihydroxystyryl)-4-hydroxy-2-pyranone by Edwards in 1961, was first isolated from the fruiting body of I. hispidus by Zopf (1889) [16]. It has also been reported that hispidin has anticancer, antibacterial, and hypoglycemic regulatory functions [16-19]. Recently, Hong Jun Shao et al. demonstrated that hispidin can inhibit the macrophage-mediated inflammatory response by downregulating NF- $\mathrm{kB}$ activation [20]. Therefore, hispidin itself is also a raw material that can be used in cosmetics. It has a superior effect compared to the existing method of absorbing raw materials through the skin by increasing the skin permeability using a micro epidermal delivery system. Antibacterial patches, whitening patches, wrinkle improvement patches, etc. can be applied using this.

However, the effects of hispidin on lipopolysaccharide (LPS)-induced macrophage reactive oxygen species (ROS) levels, phagocytosis, and cytokine production, as well as its molecular signaling mechanisms, remain unclear [13].

Herein, we developed a polylactic acid (PLA) and polycaprolactone (PCL) MN drug delivery system for hispidin. PLA and PCL were blended for high strength and effective skin permeability. On the casted PLA/PCL layer, a delivery layer was coated with PLA/PCL and hispidin. Blended PLA and PCL were optimized and compared with singlelayer-coated hispidin; the skin permeability of the composite delivery PLA/PCL layer was measured. It was confirmed that no single or mixed substance was cytotoxic. Then, when we checked the whitening effect at the optimal concentration, we found that melanin production decreased as the concentration increased. We observed the anti-inflammatory properties of PLA, PCL, and hispidin on LPS-induced RAW264.7 macrophage cells. Our results showed that PLA, PCL, and hispidin treatment significantly reduced the production of cellular nitric oxide (NO), as well as inflammatory gene RNA and protein, in a dosedependent manner. The antimicrobial activity of hispidin was measured using the paper disc method.

\section{Materials and Methods}

\subsection{Materials}

Arbutin (Sigma Aldrich, St. Louis, MO, USA), alpha-melanocyte-stimulating hormone, Sigma Aldrich ( $\alpha$-MSH, St. Louis, MO, USA), polycaprolactone (PCL, Sigma Aldrich, St. Louis, MO, USA), polylactic acid (PLA, Sigma Aldrich, St. Louis, MO, USA), dimethyl sulfoxide (DMSO, Sigma Aldrich, St. Louis, MO, USA), hispidin (TCI, Tokyo, Japan), B16F10 (Korean Cell Line Bank, Seoul, Korea), 3-(4,5-dimethylthiazol-2-yl)-2,5diphenyltetrazolium bromide (MTT, Biomax, Seoul, Korea), and a cell proliferation assay kit (Biomax, Seoul, Korea) were used as received.

\subsection{Fabrication of $M N s$}

PLA/PCL blends were prepared for the tensile strength and stability tests. PLA/PCL $(100: 0,90: 10,80: 20,70: 30 \mathrm{wt} . \%)(5 \mathrm{~g})$ was solubilized at $180{ }^{\circ} \mathrm{C}$ on a hot plate. After it completely melted, the mixture was poured immediately into a sampling mold and cooled at room temperature for 2 days. Hispidin, PLA, and PCL were coated on the $12 \mathrm{~mm}$ diameter MNs by a spin-coating process. For fabrication of coated MNs with hispidin, hispidin $(2 \mathrm{mg})$ was mixed with deionized water (DIW) $(10 \mathrm{~mL})$ until completely melted. A 
$150 \mu \mathrm{L}$ solution was raised on the center of the MNs and subject to a spin-coating process (increasing from zero to $3000 \mathrm{rpm}$ for $10 \mathrm{~s}$; increasing one more time to $5000 \mathrm{rpm}$ for $10 \mathrm{~s}$; maintaining for $10 \mathrm{~s}$; decreasing for $10 \mathrm{~s}$ ). The coated MNs were dried for $24 \mathrm{~h}$ at room temperature. For fabrication of coated MNs with hispidin, PLA $(0.08 \mathrm{mg})$ and PCL $(0.02 \mathrm{mg})$ were dissolved in DMSO $(2.8 \mathrm{~mL})$. Then, the temperature was raised to $100{ }^{\circ} \mathrm{C}$ for $24 \mathrm{~h}$ in a water bath. The solution was double-boiled in a water bath at $100{ }^{\circ} \mathrm{C}$ for $24 \mathrm{~h}$. After the melting process, the mixed hispidin $(2 \mathrm{mg})$ was melted with the PLA/PCL blended polymer. A $100 \mu \mathrm{L}$ solution was raised on the center of the MNs and subjected to a spin-coating process (increasing from zero to $700 \mathrm{rpm}$ for $30 \mathrm{~s}$; maintaining for $10 \mathrm{~s}$; decreasing for $10 \mathrm{~s}$ ). The coated MNs were dried for $24 \mathrm{~h}$ at room temperature.

\subsection{Characterization}

Mechanical properties and microstructure of MNs: The material characterization of PLA/PCL was performed using various material analyses. Tensile strength was measured using a Universal Testing Machine (LR10K Plus, LLOYD, Steyning way, BR, UK). For tensile tests, PLA/PCL blends were poured into the sampling molds and cooled for $48 \mathrm{~h}$. To determine the best properties, fabricated samples were stretched at room temperature to determine the maximum strain until fracture. After extensive tests, we obtained the stressstrain curve of each sample. Scanning electron microscopy (SEM, APREO, FEI, Hillsboro, OR, USA) was used to confirm the suitability of the coating process. We also measured the thickness of the materials by analyzing the cross-sectional area of coated MNs.

Hispidin delivery test: We estimated the absorbance using Ultraviolet-Visible-Near Infrared (UV-Vis-NIR) spectrophotometry (Lambda 750, Perkin Elmer, Waltham, MA, USA). The characteristic peak of hispidin was measured by estimating a standard curve. We estimated the absorbance of each concentration $(0.12,0.1,0.08,0.06,0.04$, and $0.02 \mathrm{wt} . \%)$ of hispidin and constructed a standard curve of hispidin. Agarose gel was used to measure the permeability of hispidin into the skin. Agarose gel is a homogeneous and semi-clear substance which mimics porcine skin for skin transitional substances [21]. The coated MNs were applied to the agarose gel ( $3 \mathrm{~g}$ ) for $5 \mathrm{~min}$ with hand pressure. After MNs were removed, agarose gel was dissolved into DMSO $(111 \mathrm{~mL})$. The amount of hispidin in DMSO was measured by UV-Vis, and the permeability of hispidin was estimated using a standard curve by comparing with a coated amount of pristine hispidin.

Cell Culture and Viability: B16F10 melanoma cells and Raw 264.7 murine macrophage cells were cultured in Dulbecco's modified Eagle's medium (DMEM) containing 10\% fetal bovine serum (FBS) and 1\% penicillin/streptomycin (GIBCO Thermo Fisher Scientific, Waltham, MA, USA). Cells were cultured in a $5 \% \mathrm{CO}_{2}$ incubator maintained at $37^{\circ} \mathrm{C}$. An MTT assay was used to ascertain the cytotoxicity of the three mixed components. B16F10 melanoma cells were dispensed into a 96-well plate at a cell number of $1 \times 10^{4}$ per well; the samples were added by concentration and incubated in a $\mathrm{CO}_{2}$ incubator at $37^{\circ} \mathrm{C}$ for $24 \mathrm{~h}$. RAW264.7 macrophage cells were seeded into 96 -well plates at a concentration of $5 \times 10^{4}$ cells per well, with different concentrations $(0 \mu \mathrm{g} / \mathrm{mL}$ to $50 \mu \mathrm{g} / \mathrm{mL})$ of hispidin, PLA, and PCL (10 to 10,000 ppm) and treated for $24 \mathrm{~h}$. Subsequently, a solution of $5 \mathrm{mg} / \mathrm{mL}$ 3-(4,5-dimethylthiazol-2-yl)-2,5-diphenyltetrazolium bromide (MTT; Quanti-Max TM, Biomax, Seoul, Korea) was added to each well and then incubated in an incubator $\left(37^{\circ} \mathrm{C}, 5 \% \mathrm{CO}_{2}\right)$ for $4 \mathrm{~h}$. A UV MAX kinetic microplate reader (Synergy MT microplate reader, BioTek, Winooski, USA) was used to measure the absorbance at $450 \mathrm{~nm}$. The experiment was conducted three times under the same conditions.

NO Production and Melanin Content Assay: The RAW264.7 cells were treated with hispidin, PLA, and PCL, as well as stimulation with LPS (lipopolysaccharide, Sigma Aldrich, St. Louis, MO, USA). NO generation was determined using Griess reagent (nitric oxide plus detection kit, Intron Biotechnology, Gyeonggi-do, Korea), with nitrite production measured according to the absorbance at $540 \mathrm{~nm}$.

Melanin Content Assay: B16F10 melanoma cells were dispensed into a six-well plate at $2 \mathrm{~mL}$ and incubated for $48 \mathrm{~h}$ in DMEM solution containing 10\% FBS. Then, $50 \mathrm{nM}$ of 
$\alpha$-MSH was added and incubated for $72 \mathrm{~h}$ at $37^{\circ} \mathrm{C}$. One day earlier, the samples were incubated for $24 \mathrm{~h}$ at $37^{\circ} \mathrm{C}$ at each concentration. After the incubation was completed, $1 \mathrm{~N} \mathrm{NaOH}$ and $10 \%$ DMSO were added to the cell pellet obtained by centrifugation at $13,000 \mathrm{rpm}$ for $5 \mathrm{~min}$; samples were boiled at $95^{\circ} \mathrm{C}$ for $20 \mathrm{~min}$, completely dissolving the melanin, and $150 \mu \mathrm{L}$ samples were transferred to a 96-well plate, followed by microplate reader measurement of the absorbance at $490 \mathrm{~nm}$. The same conditions were repeated three times to obtain an average value and calculate the amount of melanin produced in each well.

Isolation of Total RNA and RT-PCR: Total RNA was isolated with an RNeasy Mini kit (RNeasy Mini kit, Qiagen, Hilden, USA). RNA was reverse-transcribed with an oligo (dT) primer using the Super Script First-Strand Synthesis System (Intron power complementary DNA (cDNA) synthesis kit, Intron Biotechnology, Korea). RT-PCR was performed using Recombinant Taq DNA polymerase, according to the manufacturer's instructions ( $2 \times$ PCR master mix solution, Intron, Gyeonggi-do, Korea). The glyceraldehyde 3-phosphate dehydrogenase (GAPDH) messenger RNA (mRNA) level was used as a control. The following primers were used: iNOS forward 5'-GCAGAATGTGACCATCATGG-3' and reverse $5^{\prime}-$ ACAACCTTGGTGTTGAAGGC- $3^{\prime}$; COX-2 forward $5^{\prime}$-CCACTTCAAGGGAGTCTGGA-3' and reverse $5^{\prime}$-AGTCATCTGCTACGGGAGGA-3'; GAPDH forward $5^{\prime}$-ACCACAGTCCA TGCCATCAC $-3^{\prime}$ and reverse $5^{\prime}-$ CACCACCCTGTTGCTGTAGCC $-3^{\prime}$. The conditions for PCR were as follows: 30 cycles of $94{ }^{\circ} \mathrm{C}$ denaturation for $30 \mathrm{~s}, 60^{\circ} \mathrm{C}$ annealing for $30 \mathrm{~s}$, and $72{ }^{\circ} \mathrm{C}$ extension for $30 \mathrm{~s}$. The PCR products were analyzed by electrophoresis on $2 \%$ agarose gels stained with Red safe nucleic acid staining solution (Intron).

Western Blotting: Cell extracts were resolved by SDS/PAGE (BR456-1043, Bio Rad, Korea), transferred to a PVDF membrane (BR162-0177, Bio Rad, Seoul, Korea), and immunoblotted with anti-iNOS (\#2977S, Cell Signaling, Massachusetts, USA), anti-COX-2 (\#12282S, Cell Signaling, USA), or anti- $\beta$-Actin (Ab8227, Abcam, MA, USA) antibodies. Reactive bands were detected by chemiluminescence using Clarity ${ }^{\mathrm{TM}}$ Western enhanced chemiluminescence (ECL) Substrate (BR170-5060, Bio Rad, Seoul, Korea).

Strains: For the Staphylococcus aureus (Korea Collection for Type Cultures; KCTC 1916), Staphylococcus epidermidis (KCTC 1917), and Pseudomonas aeruginosa (KCTC 2153) experiments, strains from the Korea Cell Line Bank were used. After adding them to the TSA (Tryptic Soy Agar) medium, the culture was enriched for 18 to $24 \mathrm{~h}$ at 35 to $37^{\circ} \mathrm{C}$. In addition, for Escherichia coli (KCTC 1039), a strain from the same institution was used. After adding it to TSB (Tryptic Soy Broth) medium, the optical density (OD) value (600 nm) was fixed in a range of 0.760 to 0.802 for 18 to $24 \mathrm{~h}$ at 35 to $37^{\circ} \mathrm{C}$ using the method previously described (Table 1).

Table 1. Antibacterial activity according to paper disc method.

\begin{tabular}{ccccc}
\hline \multirow{2}{*}{ Treatments } & Con. $(\mu \mathrm{M})$ & & \multicolumn{2}{c}{ Size of Clear Zone $(\mathrm{mm})$} \\
\cline { 3 - 5 } & & Staphylococcus epidermidis & Escherichia coli & Pseudomonas aeruginosa \\
\hline Hispidin & 10 & 0.5 & 0.4 & 0.5 \\
Hispidin & 5 & 0.4 & 0.4 & 0.4 \\
Hispidin & 1 & - & - & - \\
Hispidin & - & 0.6 & 0.6 & - \\
$70 \%$ EtOH & $(1)$ & - & - & 0.6 \\
Sterilized DW $^{(2)}$ & - & - & - & - \\
\hline
\end{tabular}

(1) Positive control; (2) Negative control.

Measurement of Antibacterial Activity Using Paper Disc Method: The antimicrobial efficacy of each substance was measured using the paper disc method according to Murray [22]. The strain in the main culture was determined by increasing the activity under the optimal culture conditions and then incubating TSB (Tryptic Soy Broth) for about $6 \mathrm{~h}$ in the optimal medium to fix the OD value of the culture solution at 0.8 . Then, $100 \mu \mathrm{L}$ of the culture medium of each strain was evenly spread on the optimal medium in TSA (Tryptic Soy Agar); the used concentrations of hispidin were 1, 5, 10, and $20 \mu \mathrm{M} /$ disc. A sterilized paper disc (Whatman No. 5 paper, Sigma-Aldrich, St. Louis, MO, USA) was 
used after absorbing and drying the sample under aseptic conditions; samples were then cultured for $24 \mathrm{~h}$ at the optimum culture temperature of each strain, and each fraction with the diameter of the clear zone $(\mathrm{mm})$ was created around the disc. The antibacterial activity was measured, and the experiment was repeated three times to produce an average value.

Statistical Analysis: All data were analyzed using one-way ANOVA for normally distributed values. Statistical significance was determined using one-way analysis of variance followed by the Tukey-Kramer multiple comparisons post hoc test to analyze differences between groups. Statistical analyses were performed using PRISM software (GraphPad Software, San Diego, CA, USA).

\section{Results and Discussion}

\subsection{Microstructure and Mechanical Strength of MNs}

We fabricated MNs by blending PLA/PCL via the direct casting and spin-coating method (Figure 1a). The MN structure was casted as a pyramid-shaped tetrahedral structure for the transdermal delivery system. Each needle had a length of $200 \mu \mathrm{m}$ and width of $200 \mu \mathrm{m}$ (Figure 1b). Previously, pyramid shapes with widths and heights in the range of $250 \mu \mathrm{m}$ were found to exhibit effective permeability for drug delivery systems. Particularly for transdermal drug delivery (TDD), among various types of MNs, pyramid-shaped MNs can transfer drugs efficiently into the skin [23]. Furthermore, for effective drug delivery into the epidermis, we measured the tensile properties of various PLA/PCL blended structures (Figure 1c). The tensile strength of each blended PLA/PCL sample had values of $43.76 \mathrm{MPa}$ at 100:0 wt.\%, 35.42 MPa at 90:10 wt.\%, 51.26 MPa at 80:20 wt.\%, and $35.29 \mathrm{MPa}$ at 70:30 wt. $\%$. The highest ultimate strength was observed when PLA:PCL was blended at 80:20 wt.\% with a Young's modulus of $13.7 \mathrm{GPa}$. Therefore, effective physical drug delivery properties were expected to be found for the 80:20 wt.\% blend of PLA/PCL. On this MN structure, a coated type of transdermal hispidin delivery system was fabricated. For comparison, two different coated systems were developed. For the first system, dissolved hispidin solution was directly coated onto the MNs surface (Figure 1d). For another system, hispidin dissolved in PLA/PCL blended solution was coated onto the MNs surface (Figure 1e). Both samples showed sharp tetragonal MN structures even after a coating of $0.156 \mu \mathrm{m} \sim 0.372$ $\mu \mathrm{m}$ on each delivery layer.

\subsection{Hispidin Delivery Test}

To observe the delivery effects due to MN skin permeability, we replicated the system using in vitro agarose gels. The amounts of hispidin delivered to the agarose gel were calculated using UV-Vis calibration standard curves. The pristine hispidin showed the highest absorbance at a wavelength of $358 \mathrm{~nm}$, and we estimated the absorbance of each concentration $(0.12,0.1,0.08,0.06,0.04$, and $0.02 \mathrm{wt} . \%$ of hispidin) (Figure 2a). For the delivery layers, amounts of PLA and PCL were also calculated using UV-Vis calibration standard curves at $282 \mathrm{~nm}$ and $290 \mathrm{~nm}$ (Figure 2b,c). After applying MNs to agarose gel (3 g) for $5 \mathrm{~min}$, the amounts of delivered hispidin were observed. Compared to hispidin-only delivery layers, hispidin with PLA/PCL blended polymer delivery layers exhibited higher absorption peaks at $358 \mathrm{~nm}$ (Figure 2d). According to the UV-Vis calibration standard curves, $0.03 \mathrm{mg}$ of hispidin was contained on the MN surface and $0.0036 \mathrm{mg}(12.13 \%)$ was delivered from the coated $\mathrm{MNs}$ to the agarose gel. When we developed delivery layers with PLA/PCL blends, the delivered hispidin increased to $18.36 \%$. This result indicates that the high-strength biodegradable polymer offers an effective physical drug delivery system for hispidin and many other related molecules. 


\section{(a) Fabrication of PLA/PCL MNs}

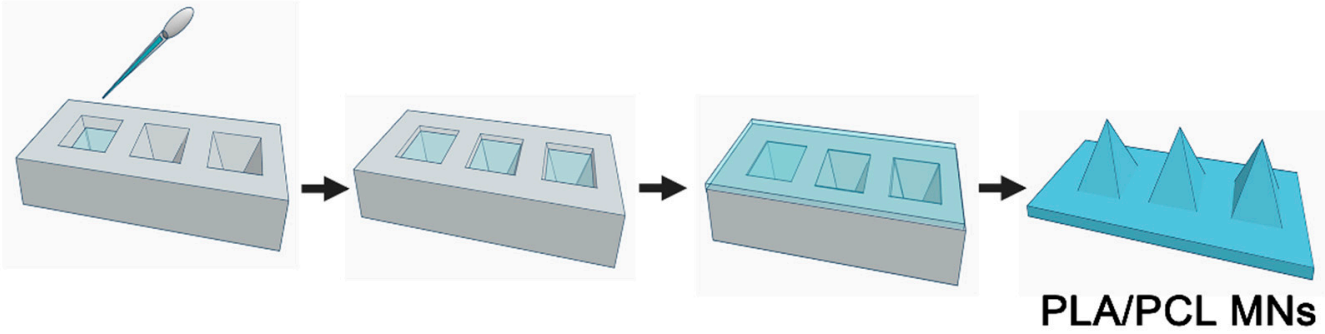

Hispidin \& PLA/PCL spin coating process
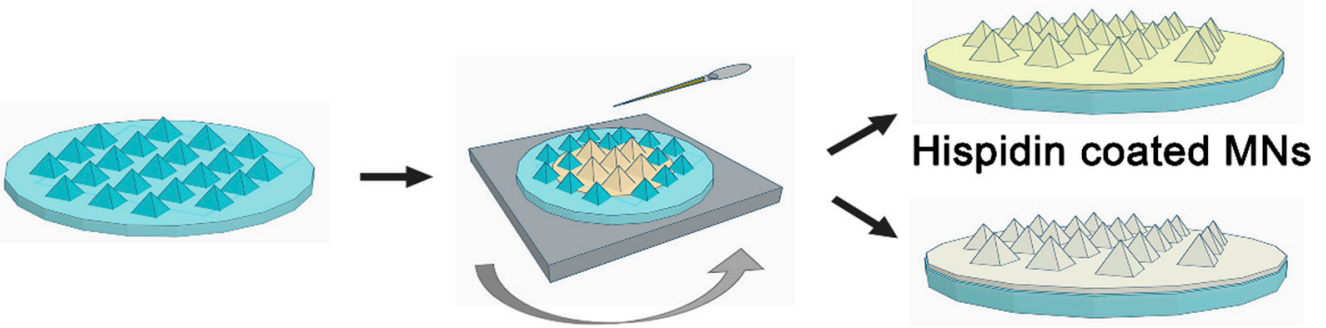

spin coating Hispidin+PLA/PCL coated MNs
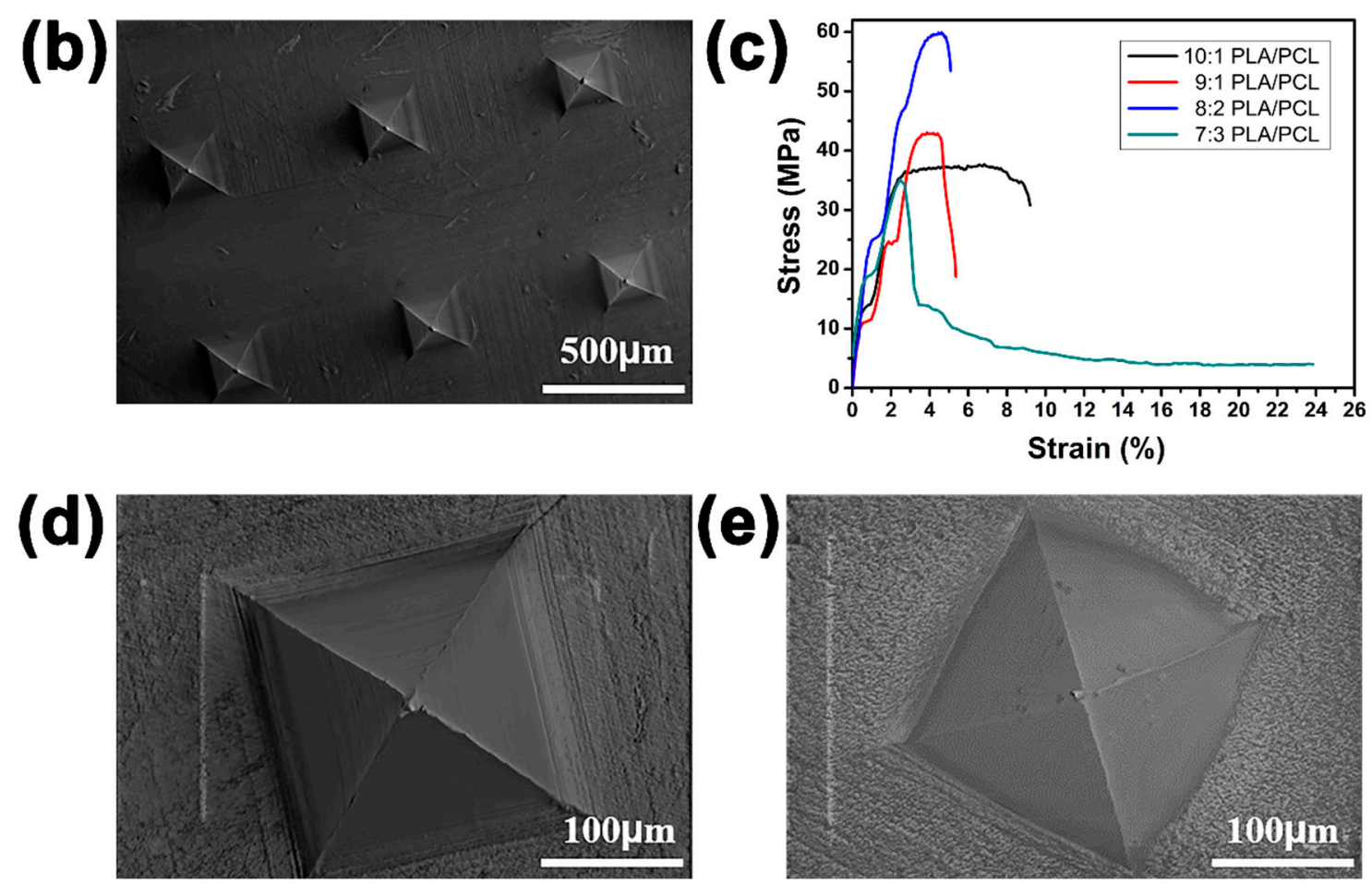

Figure 1. Microstructure and mechanical strength of microneedles (MNs). (a) Fabrication process of MNs. (b) SEM image of casted pristine polylactic acid (PLA)/polycaprolactone (PCL) MNs. (c) Stress-strain graph of various PLA/PCL blended structures. (d) SEM image of MNs after coating of hispidin delivery layer. (e) SEM image of MNs after coating of hispidin with PLA/PCL blended polymer delivery layer. 

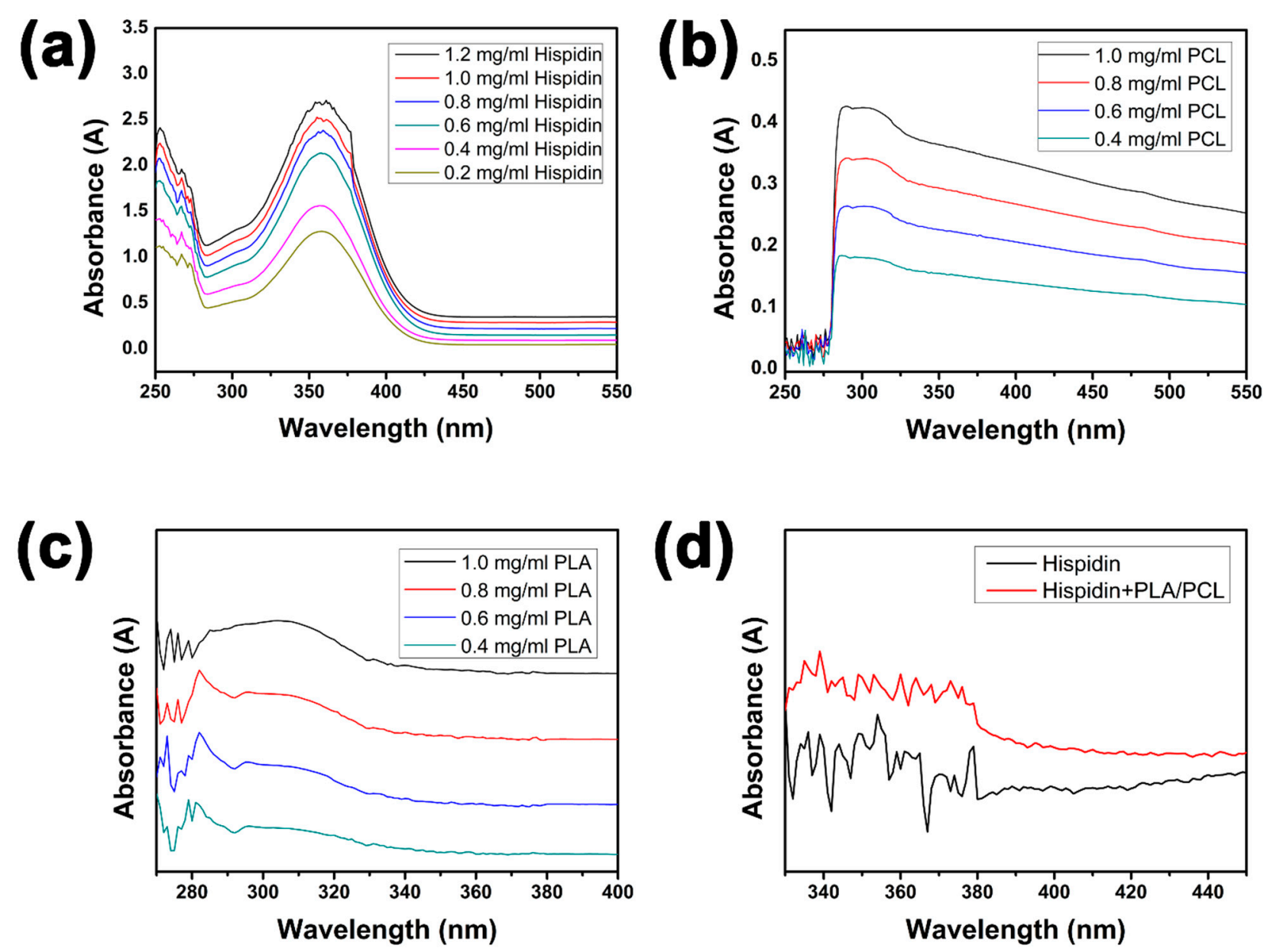

Figure 2. In vitro skin permeability of hispidin with PLA/PCL blended MNs. (a) Ultraviolet-Visible (UV-Vis) spectroscopy of hispidin, (b) PCL, (c) PLA, and (d) MN in vitro tested sample.

\subsection{Cell Viability Test with Hispidin, PCL, PLA, and Mixture}

The transdermal MN delivery system passed through the epidermis and underwent biodegradation. Once hispidin was eluted from the MNs as a solution, the effect of solution blends had a similar antibacterial activity. To determine the concentration of hispidin at which no cytotoxicity was present, B16F10 melanoma cells were treated with hispidin, PCL, and PLA in various concentrations for $24 \mathrm{~h}$. The final concentration of DMSO used was less than $0.1 \%$, which is a concentration that does not affect the cell viability. The MTT assays revealed that there were $103 \%, 95 \%, 91 \%$, and 90\% levels of viable B16F10 melanoma cells after treatment with hispidin at concentrations ranging from 1-20 $\mu \mathrm{M}$ (Figure 3a). PLA and PCL were dissolved in $1 \%$ DMSO for $24 \mathrm{~h}$ at $55^{\circ} \mathrm{C}$, giving concentrations of $10,100,1000$, and $10,000 \mathrm{ppm}$ for both materials used for the cell viability test. PLA at concentrations ranging from $10-10,000 \mathrm{ppm}$ showed values of $101 \%, 98 \%, 91 \%$, and $90 \%$ viability for B16F10 melanoma cells (Figure 3c). Furthermore, PCL at concentrations ranging from $10-10,000 \mathrm{ppm}$ demonstrated values of $121 \%, 122 \%, 119 \%$, and $120 \%$ viability for B16F10 melanoma cells (Figure 3b). Hispidin (1-20 $\mu \mathrm{M})$ mixed with PLA/PCL at the same concentration $(10,000 \mathrm{ppm})$ showed levels of $100-120 \%$ cell viability (Figure 3d). These results suggest that hispidin, PCL, and PLA, as well as their mixtures, exhibited almost identical cell viability compared to the control. 

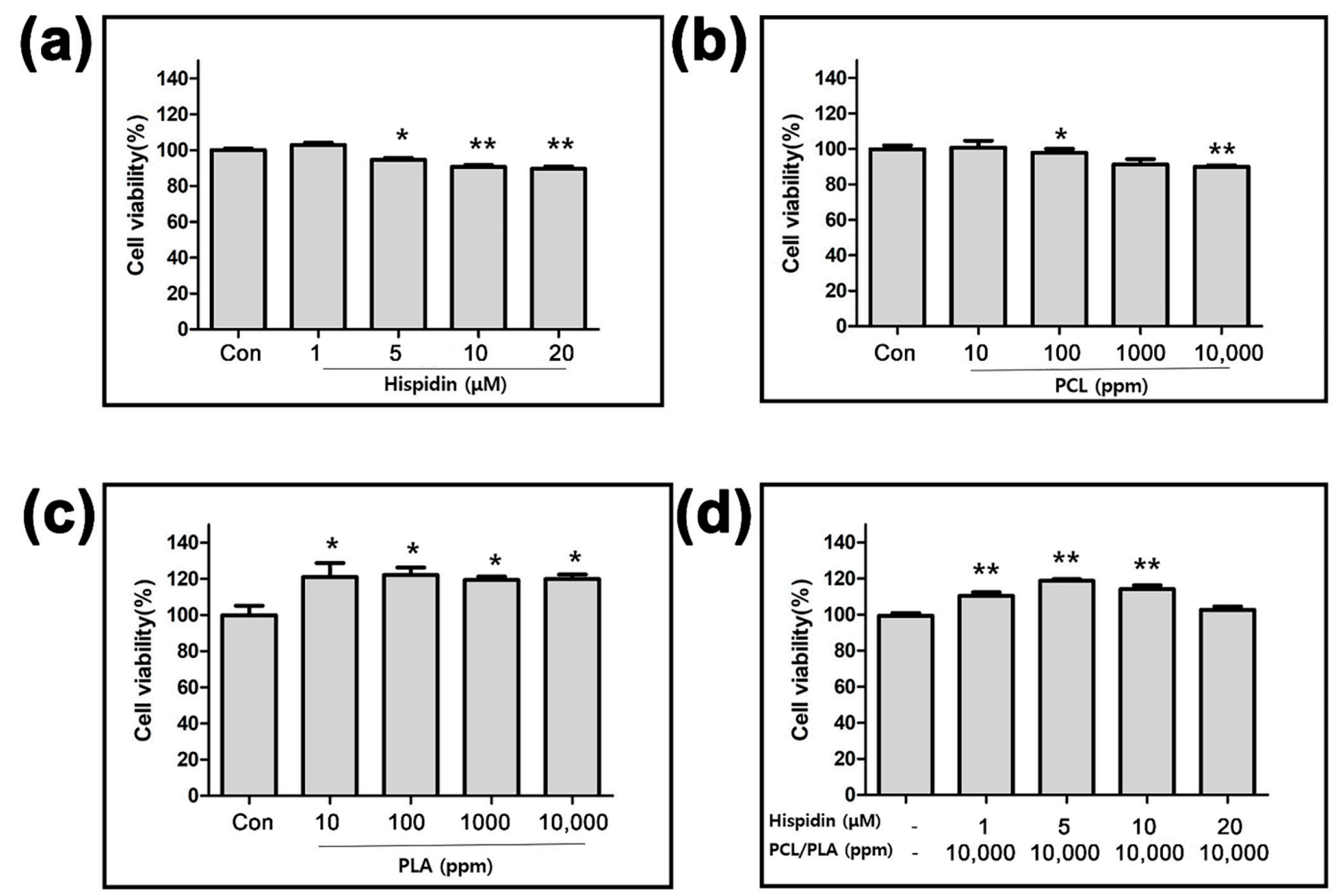

Figure 3. Cell viability test with hispidin, PCL, PLA, and their mixture in B16F10 melanoma cells. (a) B16F10 cells were treated with various concentrations $(1-20 \mu \mathrm{M})$ of hispidin, (b) PCL (10-10,000 ppm), and (c) PLA (10-10,000 ppm) for $24 \mathrm{~h}$. Cell survival was measured by 3-(4,5-dimethylthiazol-2-yl)-2,5-diphenyltetrazolium bromide (MTT) assay. (d) B16F10 cells were pretreated with hispidin $(1-20 \mu \mathrm{M})$ mixed with PLA/PCL at identical concentrations $(10,000 \mathrm{ppm}) .{ }^{*} p<0.05$, ** $p<0.01$ versus control.

\subsection{Brightening Test with Hispidin, PCL, PLA, and Mixture}

To investigate the effects of hispidin and mixtures of substances on the brightening effects using melanogenesis, the melanin contents of B16F10 melanoma cells were counted after treatment with hispidin and mixtures of the substances. $\alpha$-MSH was used as a positive control and arbutin was used as a negative control. Hispidin at various concentrations in a range of $1-20 \mu \mathrm{M}$ decreased melanin contents to $60 \%, 49 \%, 36 \%$, and $30 \%$ in a dose-dependent manner (Figure 4a). Furthermore, $1 \mu \mathrm{M}$ arbutin treatment decreased melanin content by $50 \%$ compared to $\alpha$-MSH treatment. In addition, when the mixed substances were treated, melanin contents decreased to $76 \%, 63 \%, 52 \%$, and $40 \%$ (Figure $4 \mathrm{~b}$ ). This shows that treatment with the mixed substances and hispidin significantly inhibited melanin content in a dose-dependent manner. These results suggest that hispidin, PCL, PLA, and their mixture may have powerful brightening effects.

\subsection{Anti-Inflammatory Test}

To determine whether hispidin, PLA, and PCL may have effects on macrophage cell viability, RAW264.7 macrophage cells were treated with hispidin at various concentrations $(0,1,2.5,5,10$, and $20 \mu \mathrm{M})$ and with PCL and PLA (10 to 10,000 ppm) for $24 \mathrm{~h}$. Hispidin, PLA, and PCL showed no effects on macrophage cell viability (Figure 5a-c). To examine whether hispidin has anti-inflammatory activities, the nitric oxide (NO) levels in RAW264.7 macrophage cell supernatants were examined. The results showed that treatment with hispidin, PCL, and PLA could dose-dependently decrease the production of NO in LPStreated RAW264.7 macrophage cells (Figure 5d). Furthermore, the expression levels of iNOS and COX-2 were tested according to RNA levels. Hispidin at $50 \mu \mathrm{M}$ decreased iNOS RNA levels (Figure 5e). Furthermore, hispidin treatment at $50 \mu \mathrm{M}$ significantly downregulated the LPS-induced iNOS protein expression (Figure 5f). 
(a)

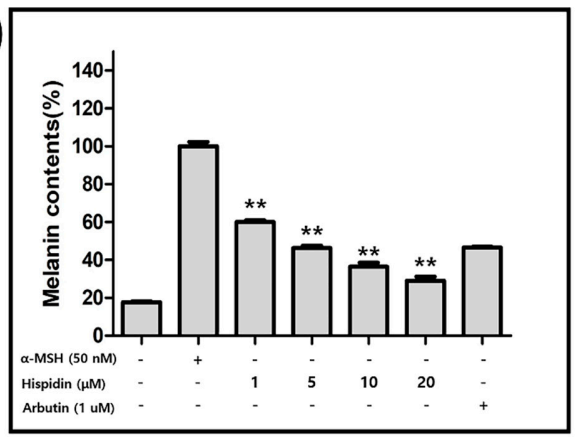

(b)

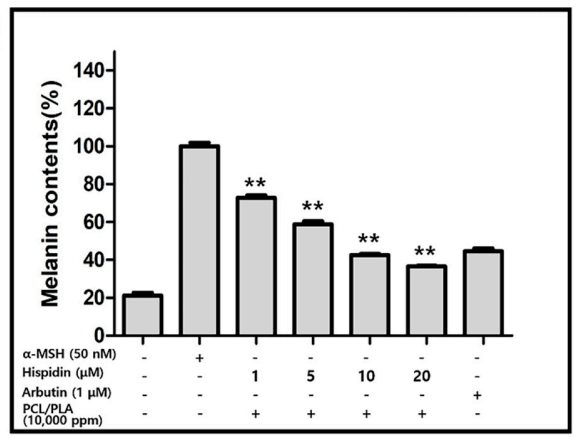

Figure 4. Effects of hispidin and mixtures of substance on melanogenesis using B16F10 melanoma cells. (a) B16F10 cells were treated with various concentrations $(1-20 \mu \mathrm{M})$ of hispidin. (b) B16F10 cells were pretreated with hispidin $(1-20 \mu \mathrm{M})$ mixed with PLA/PCL at identical concentrations $(10,000 \mathrm{ppm}){ }^{* *} p<0.01$ versus control.

(a)

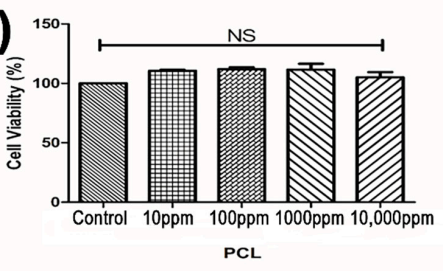

(c)

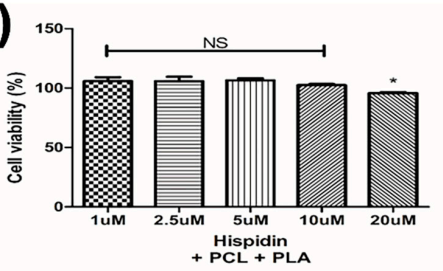

(e)

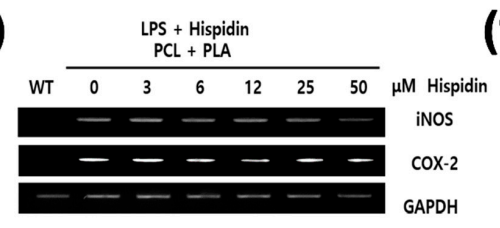

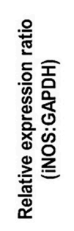
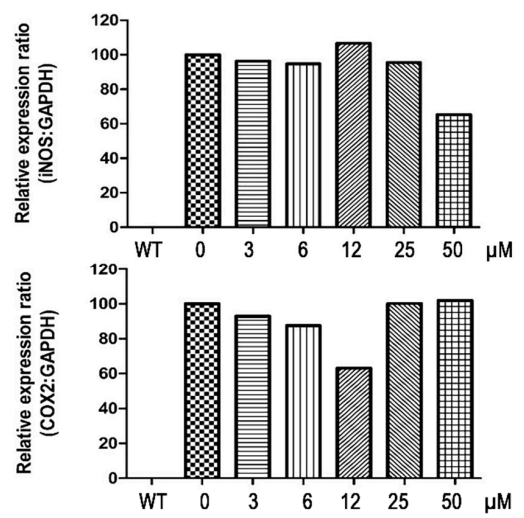

(b)

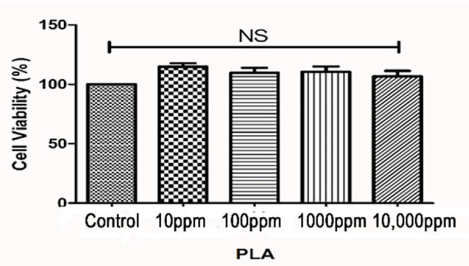

(d)

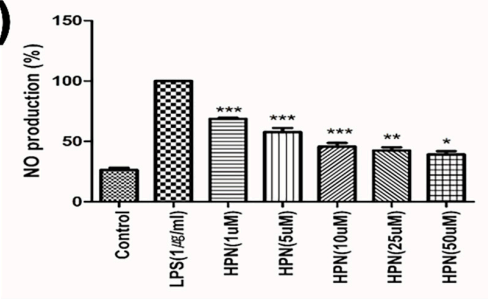

(f)
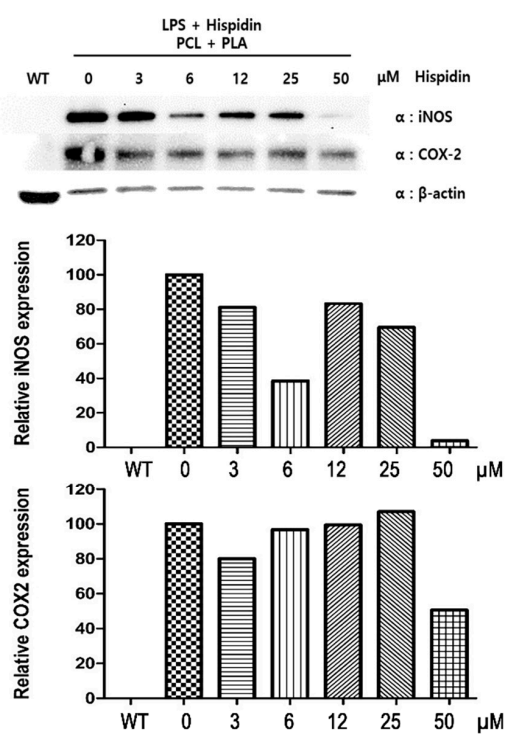

Figure 5. PLA, PCL, and hispidin inflammation in RAW264.7 cells. (a) Cells were treated with different concentrations of PLA, (b) PCL, and (c) hispidin with PLA/PCL, and incubated for $24 \mathrm{~h}$. Cell viability was measured by MTT assay. (d) RAW264.7 cells were treated with indicated treatments. Levels of nitric oxide (NO) production were measured using Griess reagent. (e,f) The RNA and protein expression levels of inducible nitric oxide synthase (iNOS) and cytochrome c oxidase subunit II (COX-2) were detected by RT-PCR and Western blot testing, and the results were quantified. ${ }^{*} p<0.05,{ }^{* *} p<0.01,{ }^{* * *} p<0.001$ versus control. 


\subsection{Antibacterial Activity by Paper Disc Method}

To measure the antimicrobial activity of hispidin, we used the paper disc method with several bacterial strains, namely, Staphylococcus epidermidis, Escherichia coli, Pseudomonas aeruginosa, and Staphylococcus aureus, as shown in Figure 6. The sizes of the clear zones for the paper disc method are shown in Figure 6; these clear zones were significantly observed from all strains (Table 1). Staphylococcus epidermidis, Escherichia coli, and Pseudomonas aeruginosa showed antibacterial activities of $10 \mu \mathrm{M}$ and $20 \mu \mathrm{M}$ at a hispidin concentration of $0.4 \mathrm{~mm}$ and of $10 \mu \mathrm{M}$ and $20 \mu \mathrm{M}$ at a hispidin concentration of $0.5 \mathrm{~mm}$, respectively (Table 1 and Figure 6). On the other hand, Staphylococcus aureus produced a $0.4 \mathrm{~mm}$ spot at a concentration of $20 \mu \mathrm{M}$ and showed antimicrobial activity at a concentration of $20 \mu \mathrm{M}$ (Table 1 and Figure 6). This indicates that hispidin might have relatively more antibacterial activity in Staphylococcus epidermidis, Escherichia coli, and Pseudomonas aeruginosa than in Staphylococcus aureus. Overall, these results suggest that hispidin may have strong antibacterial activities toward the applied surfaces.
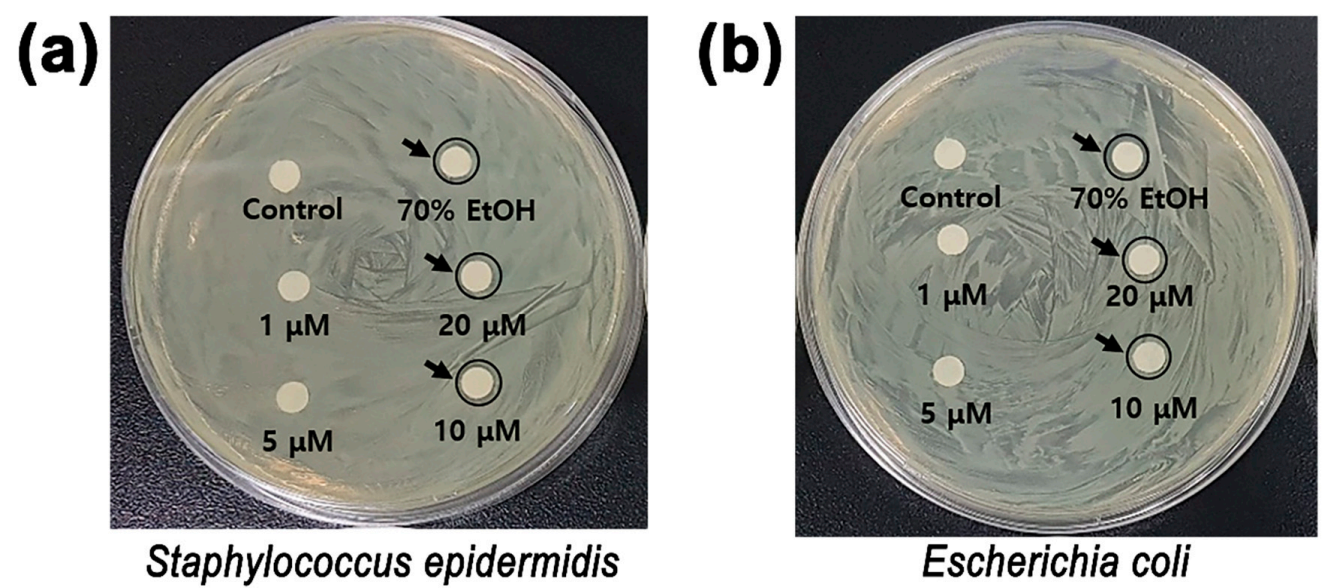

Escherichia coli
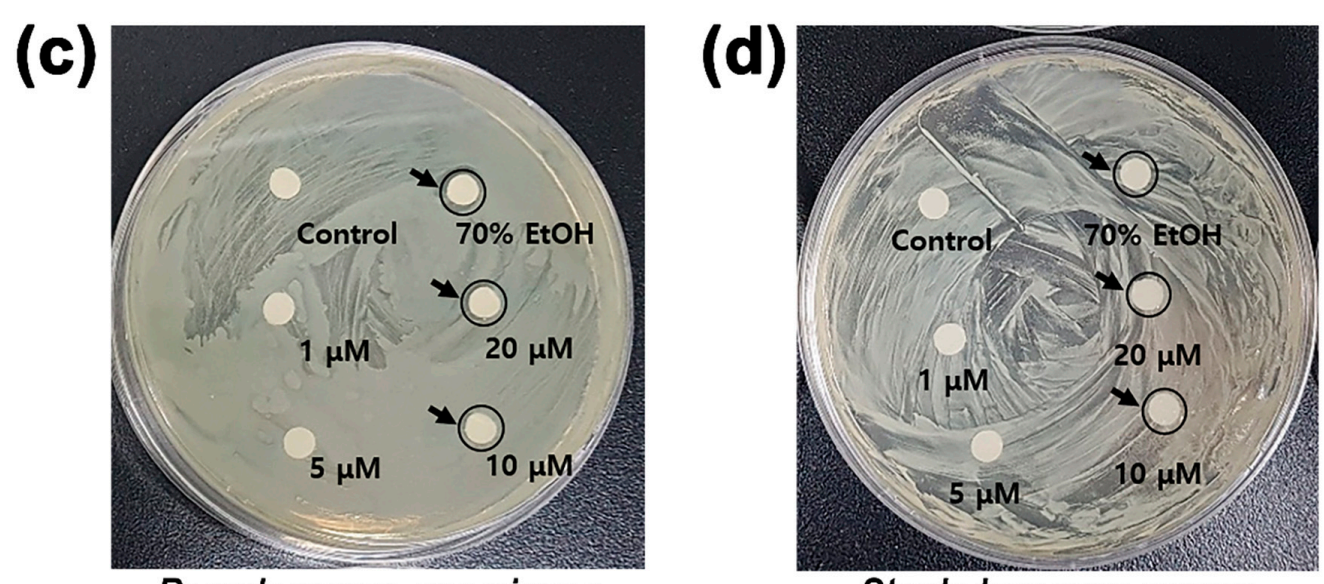

Pseudomonas aeruginosa

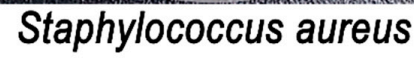

Figure 6. Antibacterial activity determined by paper disc method. (a) Staphylococcus epidermidis, (b) Escherichia coli, (c) Pseudomonas aeruginosa, and (d) Staphylococcus aureus. Hispidin concentrations were $1 \mu \mathrm{M}, 5 \mu \mathrm{M}, 10 \mu \mathrm{M}$, and $20 \mu \mathrm{M}$. The positive control was obtained using $70 \% \mathrm{EtOH}$ and the negative control was obtained using sterilized DIW.

\section{Conclusions}

Hispidin with PLA/PCL blends showed a brightening effect with anti-inflammatory activity at the gene and protein levels in skin cell culture experiments. PLA/PCL was casted using MNs for enhancing skin permeability and exhibited the highest strength of $51.26 \mathrm{MPa}$ for effective drug delivery. Compared to that of a hispidin-only delivery layer, the skin 
permeability of hispidin increased by over $50 \%$ in agarose gel in vitro tests. Hispidin coated on PLA/PCL MNs also showed a brightening effect with anti-inflammatory activity at the gene and protein levels in skin cell culture experiments. The antimicrobial activity of hispidin coating was observed in a dose-dependent manner, without cytotoxicity to skin cells. We believe that PLA/PCL MN systems with hispidin have great potential as a prototype platform for various drug delivery systems, allowing more effective delivery of subcutaneous vaccines, oligonucleotides, insulin, and many other cosmetic applications.

Author Contributions: Conceptualization, Y.P., J.K. and S.R.; methodology, S.L., J.L. and K.C.; software, S.L.; validation, S.L., J.L. and K.C.; formal analysis, S.L., J.L., K.C., H.K. and J.Y.; investigation, S.L., J.L., K.C., H.K. and J.Y.; resources, Y.P., J.K. and S.R.; data curation, S.L., J.L. and K.C.; writing-original draft preparation, S.L., J.L. and K.C.; writing-review and editing, Y.P., J.K. and S.R.; visualization, S.L. and K.C.; supervision, S.R.; project administration, Y.P., J.K. and S.R.; funding acquisition, Y.P., J.K. and S.R.; All authors have read and agreed to the published version of the manuscript. S.L., J.L. and K.C. are equally contributed.

Funding: This work was supported by the Technology development Program (S2804396) funded by the Ministry of SMEs and Startups (MSS, Korea).

Institutional Review Board Statement: Not applicable.

Informed Consent Statement: Not applicable.

Conflicts of Interest: The authors declare no conflict of interest.

\section{References}

1. Prausnitz, M.R.; Langer, R. Transdermal drug delivery. Nat. Biotechnol. 2008, 26, 1261-1268. [CrossRef] [PubMed]

2. Gupta, M.; Agrawal, U.; Vyas, S.P. Nanocarrier-based topical drug delivery for the treatment of skin diseases. Expert Opin. Drug Deliv. 2012, 9, 783-804. [CrossRef] [PubMed]

3. Ita, K. Transdermal Delivery of Drugs with Microneedles-Potential and Challenges. Pharmaceutics 2015, 7, 90-105. [CrossRef] [PubMed]

4. Bora, P.; Kumar, L.; Bansal, A.K. Microneedle Technology for Advanced Drug Delivery: Evolving Vistas. CIRPS 2008,9 , 7-10.

5. Williams, A.C.; Barry, B.W. Penetration enhancers. Adv. Drug Deliv. Rev. 2004, 56, 603-618. [CrossRef] [PubMed]

6. Sharma, D. Microneedles: An Approach in Transdermal Drug Delivery: A Review. Pharma Tutor 2018, 6, 7-15. [CrossRef]

7. Akhtar, N. Microneedles: An Innovative Approach to Transdermal Delivery-A Review. Int. J. Pharm. Pharm. Sci. 2014, 6, 18-25.

8. Li, J.; Zeng, M.; Shan, H.; Tong, C. Microneedle Patches as Drug and Vaccine Delivery Platform. Curr. Med. Chem. 2017, 24, 2413-2422. [CrossRef] [PubMed]

9. Prausnitz, M.R. Engineering Microneedle Patches for Vaccination and Drug Delivery to Skin. Annu. Rev. Chem. Biomol. Eng. 2017, 8, 177-200. [CrossRef] [PubMed]

10. Suzuki, M.; Takahashi, T.; Aoyagi, S. 3D laser lithographic fabrication of hollow microneedle mimicking mosquitos and its characterization. Int. J. Nanotechnol. 2018, 15, 157-173. [CrossRef]

11. Cheung, K.; Han, T.; Das, D.B. Effect of force of microneedle insertion on the permeability of insulin in skin. J. Diabetes Sci. Technol. 2014, 8, 444-452. [CrossRef] [PubMed]

12. Tu, P.T.B.; Chompoo, J.; Tawata, S. Hispidin and related herbal compounds from Alpinia zerumbet inhibit both PAK1-dependent melanogenesis in melanocytes and reactive oxygen species (ROS) production in adipocytes. Drug Discov. Ther. 2015, 9, 197-204.

13. Han, Y.H.; Chen, D.Q.; Jin, M.H.; Jin, Y.H.; Li, J.; Shen, G.N.; Li, W.L.; Gong, Y.X.; Mao, Y.Y.; Xie, D.P.; et al. Anti-inflammatory effect of hispidin on LPS induced macrophage inflammation through MAPK and JAK1/STAT3 signaling pathways. Appl. Biol. Chem. 2020, 63, 1-9. [CrossRef]

14. Park, J.M.; Lee, J.S.; Song, J.E.; Sim, Y.C.; Ha, S.J.; Hong, E.K. Cytoprotective effect of hispidin against palmitate-induced lipotoxicity in C2C12 myotubes. Molecules 2015, 20, 5456-5467. [CrossRef] [PubMed]

15. Maruta, H.; Tu, P.T.B.; Mok-Ryeon, A. Natural or Synthetic Anti-Melanogenic Compounds That Block the PDGFR-EGFR-PAK1MITF-Tyrosinase Signaling Pathway. J. Dermatol. Res. Ther. 2017, 3, 48.

16. Gribble, G.W. Progress in the Chemistry of Organic Natural Products, 1st ed.; Springer: Berlin, Germany, 1996; pp. 1-423.

17. Chen, W.; He, F.Y.; Li, Y.Q. The apoptosis effect of hispolon from Phellinus linteus (Berkeley \& Curtis) Teng on human epidermoid KB cells. J. Ethnopharmacol. 2006, 105, 280-285. [PubMed]

18. Lee, Y.S.; Kang, Y.H.; Jung, J.Y.; Lee, S.; Ohuchi, K.; Shin, K.H.; Kang, I.J.; Park, J.H.; Shin, H.K.; Lim, S.S. Protein glycation inhibitors from the fruiting body of Phellinus linteus. Biol. Pharm. Bull. 2008, 31, 1968-1972. [CrossRef] [PubMed]

19. Halliwell, B.; Gutteridge, J.M. Oxygen toxicity, oxygen radicals, transition metals and disease. Biochem. J. 1984, 219 , 1-14. [CrossRef] [PubMed] 
20. Shao, H.J.; Jeong, J.B.; Kim, K.J.; Lee, S.H. Anti-inflammatory activity of mushroom-derived hispidin through blocking of NF-кB activation. J. Sci. Food Agric. 2015, 95, 2482-2486. [CrossRef] [PubMed]

21. Zhang, D.; Das, D.B.; Rielly, C.D. Microneedle assisted micro-particle delivery from gene guns: Experiments using skin-mimicking agarose gel. J. Pharm. Sci. 2014, 103, 613-627. [CrossRef] [PubMed]

22. Murray, P.R.; Jo, E.; Turnidge, B. Manual of Clinical Microbiology, 9th ed.; ASM Press: Washington, DC, USA, 2007 ; pp. 1152-1172.

23. Xu, B.; Zhu, D.; Yin, D.; Jin, Q.; Gao, S.; Zhao, J. Pyramid-Shaped Tips Based Polymer Microneedles for Transdermal Drug or Nanoparticle Delivery. In Proceedings of the 2007 7th IEEE Conference on Nanotechnology (IEEE NANO), Hong Kong, China, 2-5 August 2007; pp. 287-290. 